Article

\title{
Learning Remotely during a Pandemic: Are Students in a Developing Country Fully Equipped with Tools for Swift Changes?
}

\author{
Eranda Perera ${ }^{1, *(D)}$ and Kelum A. A. Gamage ${ }^{2}$ (D) \\ 1 Faculty of Engineering, Sri Lanka Technological Campus, Padukka 10500, Sri Lanka \\ 2 James Watt School of Engineering, University of Glasgow, Glasgow G12 8QQ, UK; \\ kelum.gamage@glasgow.ac.uk \\ * Correspondence: dferanda.perera@gmail.com; Tel.: +94-704340224
}

check for updates

Citation: Perera, E.; Gamage, K.A.A. Learning Remotely during a Pandemic: Are Students in a Developing Country Fully Equipped with Tools for Swift Changes? Sustainability 2021, 13, 8635. https:// doi.org/10.3390/su13158635

Academic Editor: Marc A. Rosen

Received: 1 June 2021

Accepted: 27 July 2021

Published: 3 August 2021

Publisher's Note: MDPI stays neutral with regard to jurisdictional claims in published maps and institutional affiliations.

Copyright: (c) 2021 by the authors. Licensee MDPI, Basel, Switzerland. This article is an open access article distributed under the terms and conditions of the Creative Commons Attribution (CC BY) license (https:// creativecommons.org/licenses/by/ $4.0 /)$.

\begin{abstract}
Many higher educational institutes are forced to the online mode of lecture delivery without fully understanding students' perspectives of remote study during COVID-19, and the resource limitations of students to engage successfully in remote learning. The present study aimed to understand this gap and the students' perspective. We collected and analysed the devices, which used by the students to connect to remote learning in a developing country. It was found that the majority of students are dependent on the laptop-smartphone combination to engage in remote learning, particularly the students in rural areas. The results highlighted the importance of smartphones in the online learning experience, considering their affordability, relatively long battery life, inbuilt internet capabilities, and portability. Although students indicated their willingness for remote learning, they clearly recognised the need for face-to-face teaching return to avoid some of the challenges and disadvantages they face as a part of remote learning.
\end{abstract}

Keywords: higher education; online learning; students' perspectives of remote learning; learning technology; COVID-19

\section{Introduction \\ Overview}

Before the COVID-19 pandemic, face-to-face learning was the generally accepted mode of knowledge dissemination, and the use of technology was often limited to using learning management systems (such as Moodle, Blackboard) for many higher education institutes [1]. Particularly in the developing world, the issues related to online learning, such as limitations in devices, access to the internet, or technical know-how impeded the speedy transition to the e-learning sector [2-4]. Additionally, the learning eco-system that has been developed is one for face-to-face learning where there is a significant emphasis on using libraries, meeting lecturers and colleagues as part of the learning process [5]. In this backdrop, moving the learning process online was a risk for many higher educational institutes, where they risk alienating (fee-paying) students as well as teachers in an increasingly competitive sector.

As various levels of social-distancing measures were implemented around the world, the educational institutes and students had very little choice but to transit quickly to remote (online) learning [6]. In this process, the students were required to tap into key skills (such as digital skills) and technical experiences many have gained through preuniversity learning [7,8]. For example, despite using online tools, the learning styles adopted were similar, learning collaborations consistent, learning resources were available through e-books, articles, and websites, and the expectations from teachers needed to be met to achieve the required learning outcomes. 
As educational institutes were quickly shifting to the online mode of learning, both students and lecturers faced a range of challenges. The issues that students/lecturers faced varied from developing to developed countries $[9,10]$. In many developing countries, the accessibility to networks and devices was the main concern, whereas, in the developed world, issues related to slow internet and concerns related to the effectiveness of remote learning were widely reported.

We begin by discussing issues related to accessibility, the psychological impact of learning online, and the process of transitioning smoothly to remote education. Then we are going to explore the issue in a higher education institute in a developing country, based on a comprehensive data set on remote learning and students' perspectives. We present results from a large study group on students' perspectives of online learning including coping with online learning technologies, transitioning to online learning, knowledge, and tools used to learn, engaging in online examinations, and stress due to online learning. Then we will present a correlation analysis to understand how the students' responses varied among female and male student populations, which has not been investigated from students' perspectives in previous studies. Finally, we provide conclusions of the collected data and provide avenues for future research in the concluding section.

\section{Online Learning}

\subsection{Challenges and Benefits of Online Learning}

Remote learning had gained popularity in many developed countries due to its ability to access greater student demography at a lower cost. However, in developing countries, the online mode of learning was a less popular option but forced to use due to socialdistancing measures imposed during the pandemic. Previous literature reports some of the challenges faced by students as they shifted to online learning. In a study presented in 2020 [11], a group of English language learning students was asked about the barriers to online learning and they listed three main problems: unfamiliarity of e-learning, slow internet connection, and physical conditions such as eye strain. The students suggested that it is important to implement the learning management system before the real class, compress big data files into smaller ones and give intermittent intervals during lectures for a better experience [11]. In some other studies, similar problems of accessibility were highlighted: availability and sustainability of internet connection, accessibility of the teaching media, and the compatibility of tools to access the media [1,2]. In rural South Africa, studies revealed the challenges faced by students during the COVID-19 pandemic. Despite the government push for online learning, the mode excludes many rural learners due to a lack of resources to connect to online platforms, the learning management system, and low-tech software [12].

Despite the challenges, some educationalists have sought novel solutions to continue the learning objectives set for the year. For example, some experimented with Mozilla Hubs virtual reality platform for students to present posters and communicate with the community [13]. The main benefits of the virtual poster presentation were learning the subject matter interacting with peers; further, students received well the flexibility, novelty, and the ability to interact in an isolated environment. For the lecturers, it was experienced that the remote session was similar to a physical session. On the other hand, both students and lecturers experienced challenges with using the internet, devices, or software but these challenges were easily remedied by practice $[3,13]$. In another instance, researchers used the "Second Life" three-dimensional virtual environment [14]. The students reported the environment to be interesting and activities beneficial to overcome timidity in verbalizing in a technical forum. At the same time, the students also reported inter-campus access and sound issues.

More studies found that the inclusion of e-learning in English language education to be beneficial as it increased student interaction and sharing of information both within and outside the online space. It was noted that many students did not follow the academic rules of writing during online tasks, but they were able to apply what they learned to 
text-based assignments. Further, while it was found that incorporating online learning into the curriculum may be beneficial, it was noted that the lecturers must be careful when conducting assessments online [9]. Among students with dementia, the use of technology was found to provide high-quality care. The majority of students reported that online learning broadened their thinking and said it broadened their practice [15].

Previous research has been conducted to evaluate students' preference of different modes of learning: face-to-face, online, and hybrid (a combination of physical and online modes of delivery). According to the students' perspectives obtained from the study, the students who studied face-to-face did not indicate the learning was more effective than their peers who studied the same courses online [16]. From the analysis of students' grades, students studying face-to-face performed better than those studying online, remotelearning students said they were more satisfied with the learning experience. For online students, independent learning skills were found to be more important. For students studying face-to-face, anxiety and motivation played important roles in their preferred mode of learning environment and the effectiveness of their learning. In the same study, it was noted that the factors most appreciated by students are the skills of the lecturers and the usefulness of the course. Further, it was shown that using technology increases understanding of the material and promotes greater interaction during the delivery, and also technology use seemed to increase the level of autonomy and motivation.

In further research, it was found that the students were generally technically competent and issues associated with equity and access varied among students in the same department [17]. Further, the students had reconceptualized what is understood as 'personal' study spaces as physical proximity among students in learning did not become a factor in online learning. In some studies, such as in medicine, where physical practice is essential, the researchers reported the advantage of having initial face-to-face teaching before shifting to the online mode. It was recommended that a hybrid learning approach with both face-to-face and also online learning has the potential to provide the necessary knowledge to skilled dementia care practitioners [15]. Furthermore, research has shown students' interest in remote learning, in particular, mobile-based education: the authors of [17] showed behavior patterns of medical undergraduate students preferring mobile technology for learning and willingness to recommend it.

Previous literature also reports that students generally view themselves as having the necessary attributes to be good online learners. Generally, students enrolled in qualitative courses and introductory classes showed more positive perceptions of online learning and various aspects of coursework than those who are in quantitative courses and advanced level classes [8]. Another study explored nursing students' views on online learning [4]. It was found that online learning enabled students to hold a higher level of accountability for their own learning and be independent learners. On the other hand, students complained about reduced peer interaction which was needed for group discussions/projects. Furthermore, it has been noted that the online learning environment can be used to integrate students from different parts of the world by the appropriate use of discussion boards and other learning strategies which would yield many benefits to students [18]. Despite the conventional wisdom, some researchers reported that it is possible, with careful design and delivery, to successfully deliver foundational outdoor education modules [19].

\subsection{Psychological Impact of Online Education}

Some researchers have attempted to understand the effectiveness of online learning from a psychological point of view. For example, a study was conducted to understand the relationship between the used amount of working memory resources (i.e., cognitive load) and student satisfaction with learning online [20]. It was found that there is a positive correlation between cognitive load and student satisfaction with online learning. Furthermore, $25 \%$ of the variance in satisfaction with learning online was found to be related to cognitive load. 
It has been theorized by some researchers that online learning can be viewed as online participation [21]. According to the theory, if we want to improve online learning, we have to improve online learner participation. It is outlined that online learning is a complex process of participating and maintaining relations with peers and lecturers, supported by physical and psychological tools, not synonymous with oral or written expression of information, and is supported by all kinds of engaging activities.

A team of researchers conducted a survey among 255 students in an online university to understand the direct and indirect social factors that affected learners' engagement online. It was found that social support provided by teachers was the only interindividual factor that influenced students' engagement. Additionally, a sense of community was also found to be a significant predictor of online learners' engagement [22].

Furthermore, researchers have explored the possible link between student satisfaction with online learning and the predetermined but unspecified expectations for online courses by both students and lecturers [23]. The results identify three main satisfaction components: engaged learning, agency, and assessment. In the analysis, it is found that the satisfied students characterize important differences in engaged learning and agency, but not assessment.

\subsection{Transition to Online Learning}

A study presented in [24] collected data from 270 students to explore college students' perceptions of their adoption, use, and acceptance of emergency online learning during COVID-19. It was pointed out that educational institutes should not assume that online learning has the same effect as emergency online learning. In such a pandemic, the delivery of lectures has to be a creative and flexible emergent response to a particular crisis. It demands greater thought and clear communication between all involved parties than previous educational experiences as this is unique to the emergency. The results showed there was a downward trend for motivation, self-efficacy, and cognitive engagement, but a positive trend for the use of technology, after the transition to online learning. Further, face-to-face learning was preferred by the surveyed students as this mode of learning has developed an overall ecosystem designed to support learners [24].

A study was conducted to analyze the experience of converting three modules from physical mode to online mode of delivery as a response to the pandemic [6]. During the transition, the lecturer's role also shifted towards curation of online and offline student experience which included providing blended online learning experiences. In this process, it was needed to create learning roadmaps to facilitate student learning and improve online engagement between students and lecturers. It was noted that online learning provides opportunities to adapt learning experiences on the go.

Some researchers in Pakistan surveyed 126 undergraduate and postgraduate students to analyze students' perspectives of online learning and found that the majority of students overwhelmingly preferred face-to-face learning [25]. For the unpopularity of online learning, it is outlined that it is affected by internet accessibility issues and economical issues. Further, it was reported a lack of interaction with lecturers, response time, and absence of traditional classroom socialization as key factors for this unpopularity. As a result of no on-campus socialization, a significant proportion of students said they found it difficult to do group projects. Considering all the difficulties of making the transition, it was reported that the majority of the students did not want to pursue online learning after the pandemic and it was highlighted that the mode may not be effective, especially for developing countries. This suggests the importance for educational institutes to improve curriculum and design appropriate content for online lectures [25].

In Zambia, some researchers provided evidence that mathematics teachers can also learn via using online tools [26]. However, it was found that there are significant mean differences between sample groups suggesting possible differences in attitudes towards the use of technology in learning. For this variation in attitudes, it is suggested that lack of skill 
and knowledge in using online tools, unstable electricity connections, unaffordable internet costs to sustain long hours of online learning dissuade away from online learning [26].

A group of researchers conducted a study among 60 undergraduate medical students aimed to explore undergraduate students' perceptions regarding the effectiveness of synchronized online learning [27]. It was found that the online mode of learning was well-received, and all participants agreed remote learning was time-saving and that their performance improved due to effective time management. However, they also reported that they faced challenges in methodological, content perception, technical, and behavior during online sessions. A majority of preclinical students indicated their preference for online learning for future academic years. The researchers pointed out that the online mode of learning has a significant and promising potential tool for medical education, however, the online learning model and learning outcomes must be rigorously and consistently assessed to check effectiveness [27].

\section{Methodology}

\subsection{Details of the Survey}

A survey was conducted among 951 undergraduate students in a Sri Lankan nonstate university, Sri Lanka Technological Campus, using an online survey addressed to all undergraduate students studying in the university. In the online survey, it was clearly stated that the anonymity of the students would be protected in the data collection and analysis. In terms of learning resources, the university was one of the better prepared in the country for the transition to online education. The undergraduate students were selected due to the large sample size and diversity in the programs that they are studying in the university. From a total undergraduate student population of nearly 1500 at the time of data collection, the present sample is very closely representing the true student perspective.

The survey is aimed to collect information about the devices used by students, the preferred mode of lectures, and students' perspectives on their learning experience, tools used, and the competency of lecturers on delivering lectures online. The survey was conducted nine months after the institute had shifted to the online mode of lecture delivery due to the COVID-19 nationwide lockdown. Before this shift, the surveyed students had not previously engaged in continuous online learning, and the lecturers also had limited, if any, experience in delivering lectures through online platforms.

In the present survey, the participants were from diverse backgrounds as shown in Figure 1: 495 engineering students (337 male and 158 female), 148 technology students ( 87 male and 61 female), 193 business students (60 male and 133 female), 95 IT students (58 male and 37 female), and 20 music students (6 male and 14 female). The students studied various programs at their respective schools. Although at varying levels, all students relied on online lectures, remote interactions for assignments and other group projects, and online examinations. In this paper, we aim to study the general perspectives of these students on matters related to online learning across a range of programs.

Firstly, the survey results of all the schools are analyzed for the devices used, then various questions regarding students' perspectives on online learning and accessibility issues were analyzed including:

1. Coping with online learning technologies,

2. Transition to online learning,

3. Knowledge and tools to learn,

4. Competency of lecturers on online technologies,

5. Engaging in online exams,

6. Stress due to online learning,

7. Delaying learning until the end of the pandemic. 


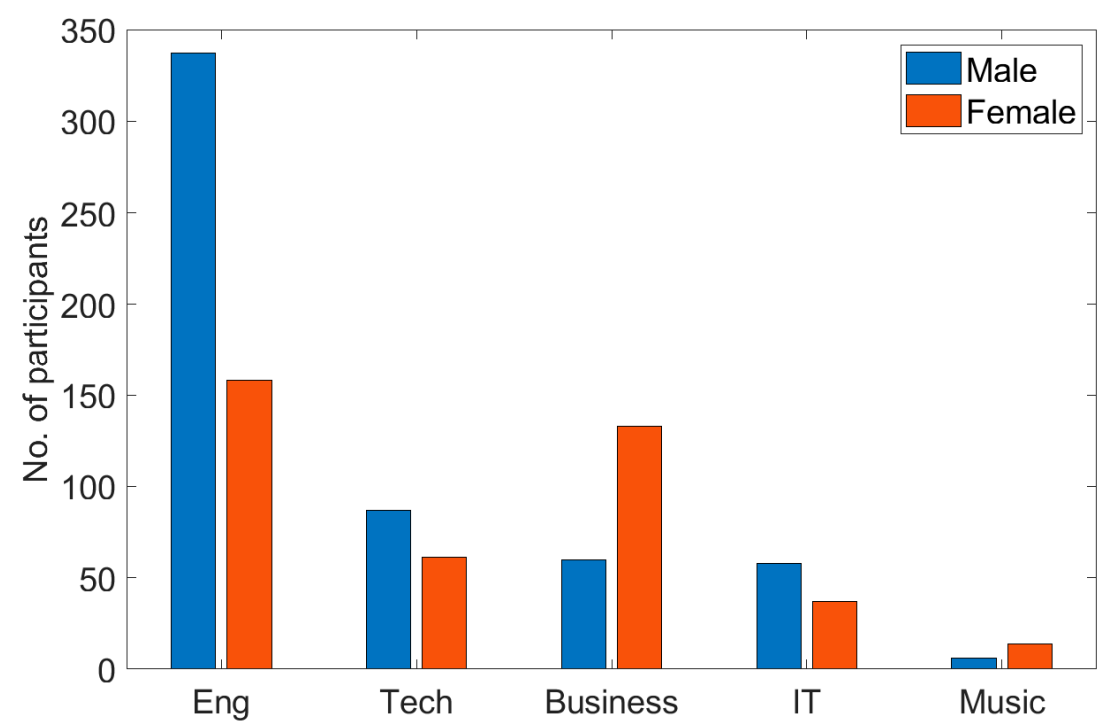

Figure 1. Distribution of participants across the schools.

\subsection{Method of Analysis}

In the present survey, many student responses were collected on a five-point Likert scale. At the stage of analysis, authors contemplated on whether to use a parametric or non-parametric type of analysis, considering the long-standing debate over the use of Likert scale data [28]. Over the years, many statisticians have argued about the validity of using Likert scale data as continuous data, especially considering that it is difficult to judge the intensity difference between groups, for example between "Very Badly" and "Badly" may not be the same intensity difference as "Well" and "Very Well", therefore it is difficult to assume constant intervals [28]. Additionally, if responses are clustered at the high and low extremes, the applicability of parametric tests may be put into doubt as well. At the same time, [28] suggests if there is a significant data sample and the data agrees reasonably well to a normal distribution, then it is acceptable to use parametric methods of data analysis. This statement is also supported in the work of [29] who used parametric analysis for Likert scale data in the field of medical education research.

In the present study, we asked questions from students using the five-point Likert scale as very badly (strongly disagree), badly (disagree), indifferent (undecided), well (agree), or very well (strongly agree). The collected data sample of 951 (out of nearly 2000 total population) students is reasonably considered to be a large sample, with more than 10 responses per group. Then the Chi-square test is conducted for each sample of Likert data collected to check the null hypothesis that the data collected come from a population with a normal distribution. In each of the tests conducted, we found that the null hypothesis is rejected at the 5\% significance level. This led to the authors analyzing the data using the non-parametric Mann-Whitney U method and using median and mode as the "measure of central tendency" because the statistical approaches required to calculate the mean and standard deviation are not recommended for ordinal data [30].

After collecting the data using online forms, we processed the collected data using MATLAB and visualized the results for analysis.

\subsection{Data Validation}

The device usage results presented in the paper were validated by comparing the results against a pilot survey previously conducted for engineering students from the same university just 09 months prior to the present survey as shown in Figure 2. In the pilot study, we collected anonymous student responses from 331 engineering students (both male and female). The relatively small-time difference between the two surveys, and intermittent national lockdowns in this period, ensured that the survey results were comparable for result validation. After comparison, it was seen that the present survey 
showed very close outcomes with regards to the device used by calculating percentage difference using

$$
|(a-b)| / a \times 100,
$$

where $a$ is the percentage of device usage in the present survey results and $b$ is the percentage of device usage in the pilot survey.
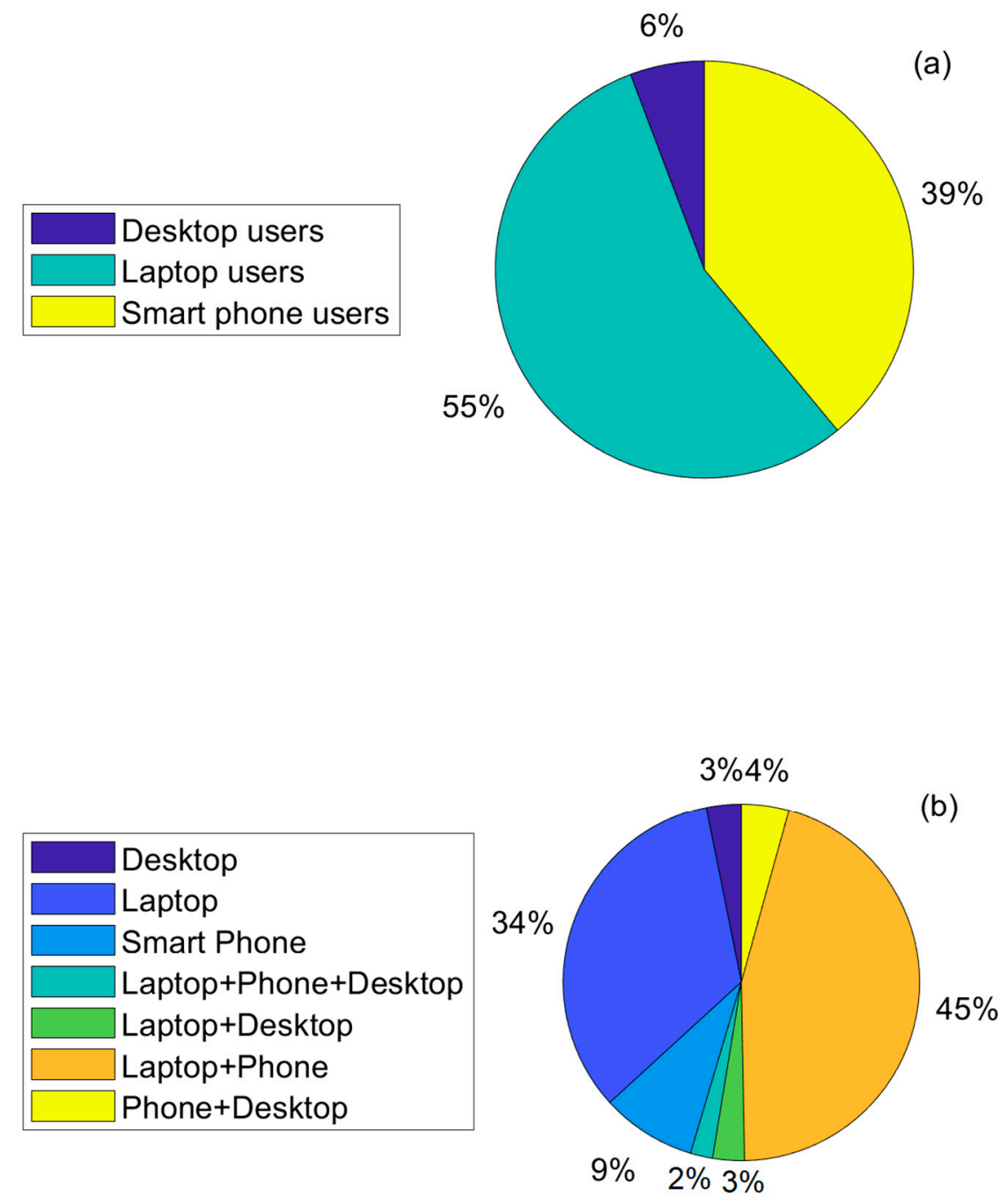

Figure 2. Pilot questionnaire results among engineering students for (a) devices used by participants and (b) device combinations used by participants to access online learning.

The percentage differences in using desktop 20\%, laptop 5.77\%, smartphones $4.88 \%$. Additionally, the percentage difference of using combinations of laptop and phone $9.76 \%$, laptop only $0 \%$, smartphone only $47 \%$ when compared to Figure 2 . After the validation, we continued to test students' opinions on a wide range of areas.

From the key questions we asked as seen in Section 2.1., we also tested the reliability of the responses obtained by conducting a correlation study between each response. We used the non-parametric Pearson-Rho correlation test for the ordinal Likert data collected through the survey. It was found that there was a high correlation (close to 1) between both groups of students (male and female) between the surveyed topics as shown in Table 1. This correlation study allowed us to gain higher confidence in the reliability of the data we collected through the online form. 
Table 1. Correlation analysis results using Pearson-Rho test (blue color refers to the male population and orange color refers to the female population).

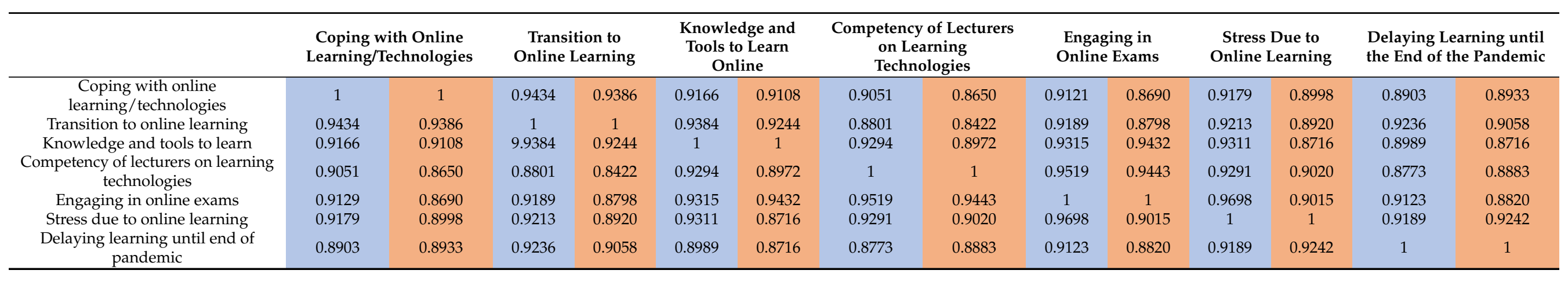




\section{Results and Analysis}

\subsection{Devices Used to Connect to Online Lectures}

The results shown in Figure 3a demonstrate that the most preferred devices for online learning are in the order of laptop (52\%), smartphone (41\%), desktop (5\%), and lastly tablet $(2 \%)$. Furthermore, it is found that the most preferred combinations of device use are laptop and smartphone (41\%), laptop only (34\%), and smartphone only (17\%) as shown in Figure $3 \mathrm{~b}$. The greater reliance on laptop and smartphone combinations indicates the possibility that students are depending on mobile internet to connect to lectures, especially in rural parts of the country. In rural parts of the country, it would be expensive to set up a learning station that includes a device with internet facilities due to low network connectivity and the need for additional devices such as modems and routers. Additionally, smartphones may be used as a second device/backup when attending lectures due to their relatively longer battery life, greater portability, and easier accessibility due to lower cost.

(a)

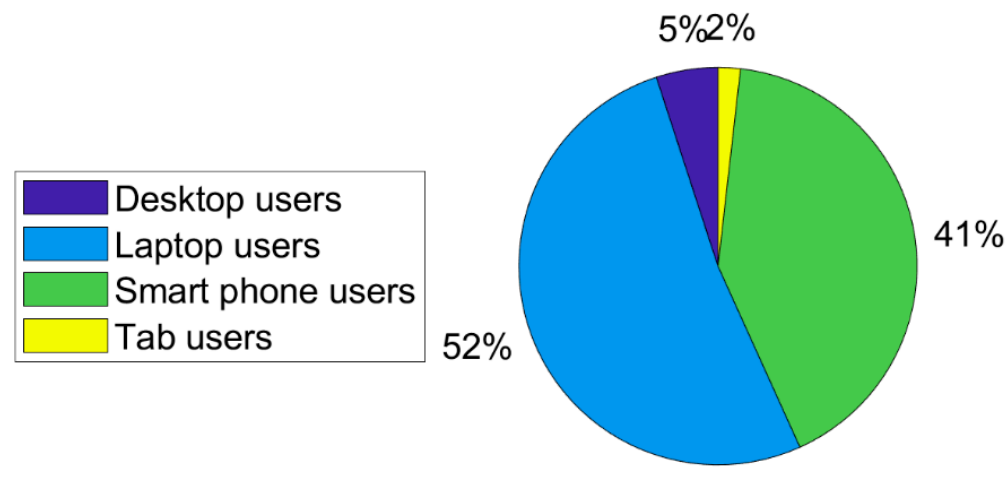

(b)
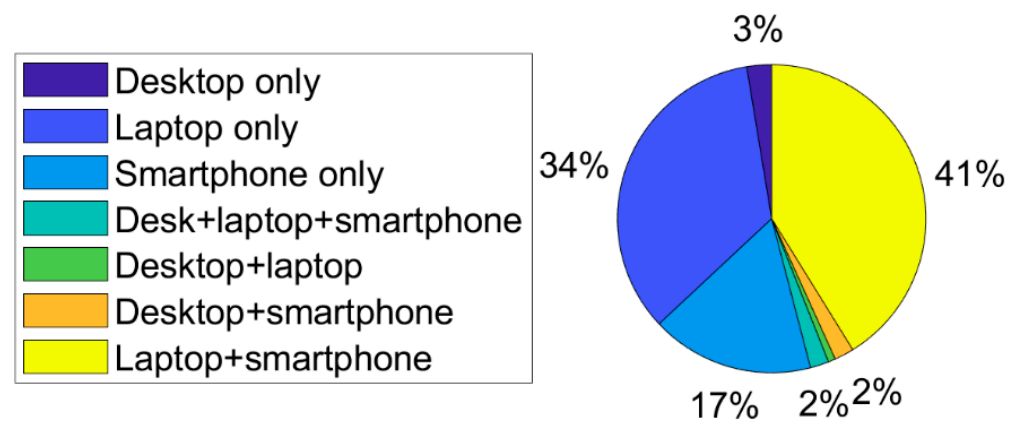

Figure 3. (a) Devices used by participants and (b) Device combinations used by participants to access online learning.

It is noted that there is a significant proportion of users of smartphones as their only mode for attending lectures. Again, this could potentially be more prevalent in rural parts of the country where access to WiFi connections is limited, therefore users depend on mobile internet for internet access. Conversely, it is noted that a very low proportion of students stated that they are using a desktop as their only mode for attending lectures. The desktop computers could be seen as bulky, expensive, and difficult to set up to attend online lectures. These trends highlight the importance of portability, the presence of 
in-built network components, and the cost of choosing the device for online learning. It is also noteworthy that the smartphone emerged as a great equalizer for education by providing greater access to rural, less-connected communities to also have access to learning. While the internet does provide much free learning material, without a suitable device, it would not be possible to maximize the benefits the internet provides. Perhaps, in the post-COVID world, we could observe further improvements and development in smartphone-based learning for a larger range of age groups, especially within institutions based in developing countries.

\subsection{Preferred Mode of Lecture Delivery}

Next, we asked students about their preferred mode of lecture delivery providing three main options in the questionnaire: face-to-face learning (traditional method), online learning where lectures are solely delivered through virtual platforms synchronously, and hybrid which is a combination of physical and online lectures. In the hybrid method, the lectures are delivered physically but they are recorded and made available to students through a learning management system to access asynchronously.

It is noted that the most preferred mode of delivery among the surveyed students is face-to-face learning as shown in Figure 4. This is followed up by hybrid and online modes of lecture delivery in this order. However, there is an insignificant difference between the two modes. Furthermore, if the students indicating a preference for hybrid and online learning are grouped together, they would outnumber those who expressed a preference for face-to-face learning. In both online and hybrid modes of learning, recorded lectures, which can be viewed at the students' convenience, would be available. This indicated that the students are perceiving the value of remote learning through the pandemic.

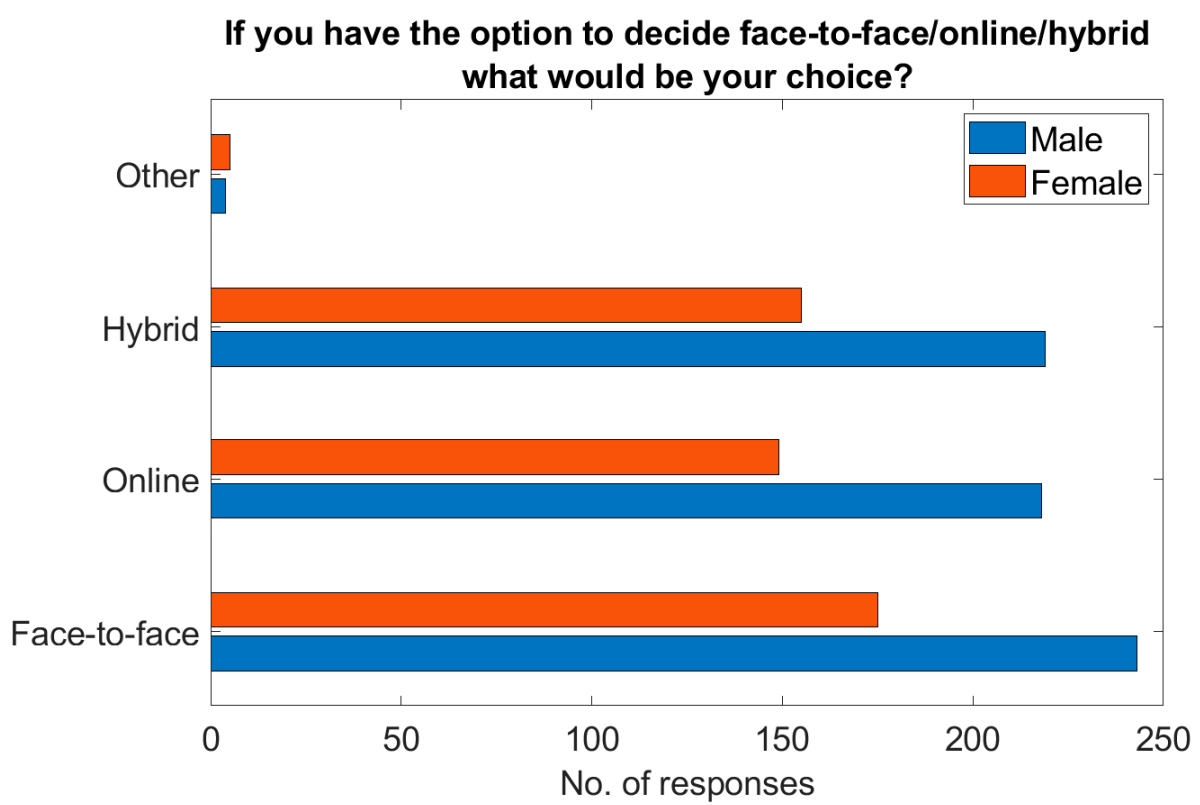

Figure 4. Student responses to "if you have the option to decide face-to-face/online/hybrid learning, what would be your choice?"

Additionally, some students who took the survey voiced their opinions, at length, on their preferred mode of lecture delivery:

(1) "Extra reading methods, (such as) books (are needed)", student, Business School, which indicated the students' natural affinity towards referring books in the library in a physical setting. At the same time, another student said:

(2) "This method (online mode) is boring because we do not understand (well). Nothing is better for us than learning face to face", student, Business School. 
This shows that some students did not find it interesting to learn through online platforms and they needed physical interactions to comprehend concepts. Another student outlined that learning through online platforms can only be done for certain modules which allow this luxury and some need a more practical, face-to-face approach to be effective:

(3) "There are some modules which can entirely be done via online. Also, there are some modules which cannot be done via online-it needs to be face to face. I will say (it) again, some CANNOT be done online", student, Business School.

Finally, another student said he found online exams to be difficult which could be due to factors such as poor connectivity and device-related issues:

(4) "Lectures (in) online mode (is) okay. But (I am) fed up with online exams", student, School of Engineering.

\subsection{Transition to Online Learning}

\subsubsection{Smoothness of the Transition to Online Learning}

In this institution, in March 2020, the surveyed students were forced to switch to learning through online means due to the nationwide lockdown triggered by COVID-19. In the present survey, we obtained the students' perspective of the transition made to online learning during this period. It is reported that the majority of both male and female students agreed that they had a smooth transition to online learning, which is followed up by those who were undecided and those who disagreed with the premise entirely, as shown in Figure 5a. Both male and female results show that they are continuous samples with equal medians (null hypothesis $\mathrm{h}=0, p>0.05$ ) as shown in Table 2 . The median/central tendency of the results is indicated to be "undecided" on the topic as shown in Table 2.

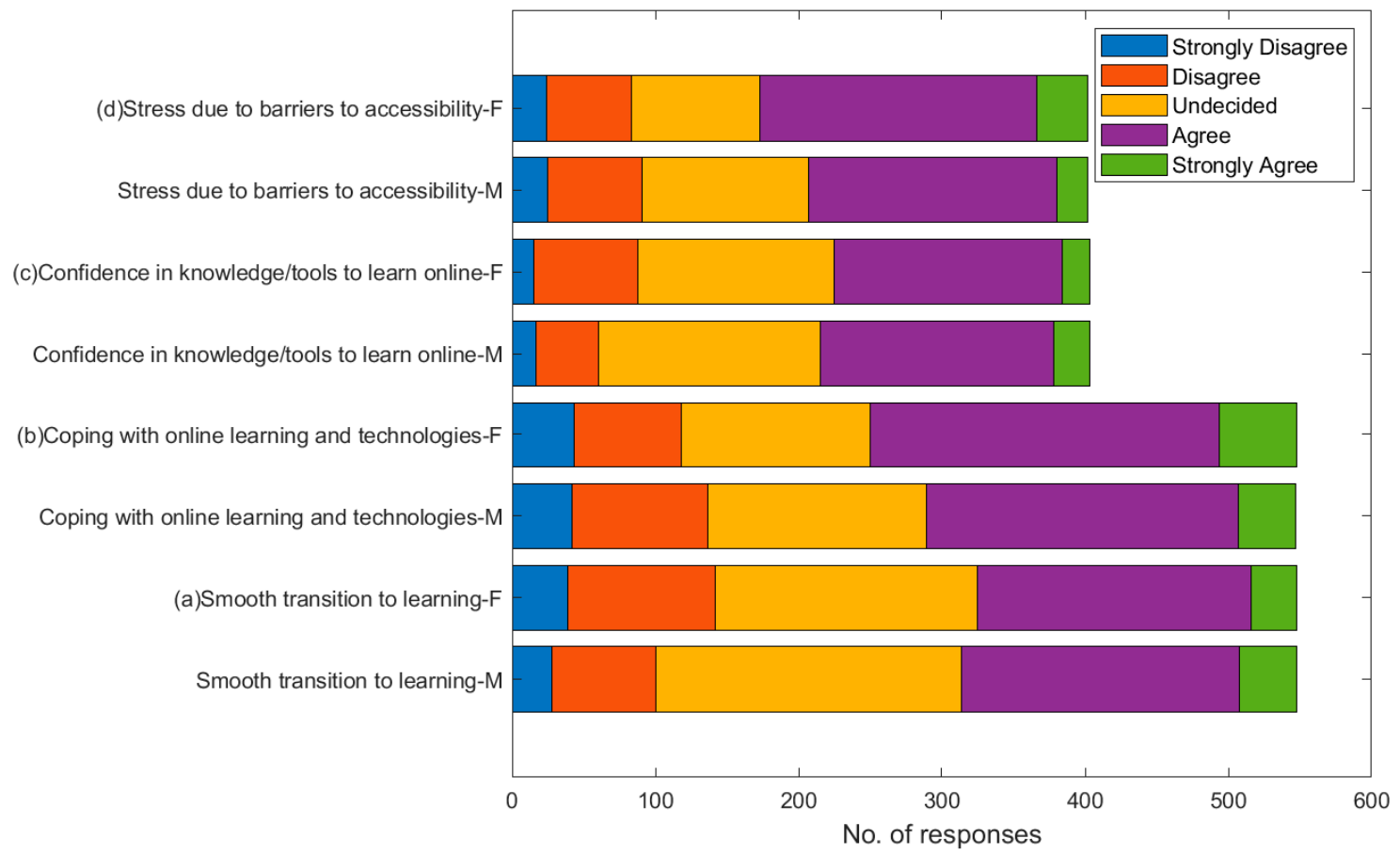

Figure 5. Student responses ( $\mathrm{M}$ - male; F-female) to (a) Do you feel you had a smooth transition to online learning? (b) How well are you coping with online learning and technologies? (c) Do you feel confident about the knowledge and tools to learn online? (d) Do you feel stressed as a result of barriers to accessibility of technology? 
Table 2. Mode, mean, and Mann-Whitney U test results for the survey results.

\begin{tabular}{|c|c|c|c|c|}
\hline \multicolumn{5}{|c|}{ Transition to Online Learning } \\
\hline & \multicolumn{2}{|c|}{ Central tendency } & \multicolumn{2}{|c|}{ Mann-Whitney U test } \\
\hline & Mode & Mean & $\mathrm{h}$ (null hypothesis) & $p$-value \\
\hline Male & 3 & 3.1350 & \multirow[b]{2}{*}{0} & \multirow{2}{*}{0.1725} \\
\hline Female & 3 & 3.2333 & & \\
\hline \multicolumn{5}{|c|}{ Coping with online learning and technologies } \\
\hline & Mode & Mean & h (null hypothesis) & $p$-value \\
\hline Male & 3 & 3.2664 & \multirow[b]{2}{*}{0} & \multirow{2}{*}{0.2189} \\
\hline Female & 3 & 3.3375 & & \\
\hline \multicolumn{5}{|c|}{ Confidence about the knowledge and tools to learn online } \\
\hline & Mode & Mean & h (null hypothesis) & $p$-value \\
\hline Male & 3 & 3.2176 & \multirow[b]{2}{*}{0} & \multirow{2}{*}{0.6789} \\
\hline Female & 3 & 3.2512 & & \\
\hline \multicolumn{5}{|c|}{ Stress due to barriers to accessibility of technology data } \\
\hline & Mode & Mean & h (null hypothesis) & $p$-value \\
\hline Male & 4 & 3.3613 & \multirow{2}{*}{1} & \multirow{2}{*}{0.0014} \\
\hline Female & 4 & 3.6030 & & \\
\hline
\end{tabular}

\subsubsection{Coping with Online Learning and Technologies}

It is reported that most male students expressed indifferent opinions of online learning, followed by coping "well" and "badly". At the same time, most female students said that they are coping well with online learning, followed by coping "indifferently" and "badly" as shown in Figure 5b. Overall, both male and female results show that they are continuous samples with equal medians (null hypothesis $\mathrm{h}=0, p>0.05$ ) as shown in Table 2. The median/central tendency of the results is indicated to be indifference on the topic as shown in Table 2.

\subsubsection{Confidence in the Knowledge and Tools to Learn Online}

For the present study group, the synchronous lecture delivery was conducted through Zoom, and learning material and assignments/coursework/examinations were conducted through the learning management system Moodle. With this background, we asked students whether they feel confident about the knowledge and the tools available to learn online and report our findings in Figure 5c.

We observed similar response trends between male and female students. It was noted that the majority of students agreed that they feel confident about the knowledge and tools available to learn online, which is followed by those who were "undecided" and "disagreed" with the premise entirely. It could also be noted that the number of students, both male and female, who stated they strongly agreed or strongly disagreed were more or less the same. Overall, it could be observed that the students felt positive about the knowledge and tools made available to learn through online mode. Both male and female results show that they are continuous samples with equal medians (null hypothesis $h=0$, $p>0.05$ ) as shown in Table 2. The median/central tendency of the results is indicated to be "undecided" on the topic as shown in Table 2.

\subsubsection{Stress Due to Barriers to Accessibility of Technology}

We asked the students whether they feel stressed as a result of barriers to accessibility of technology as shown in Figure 5d. The results showed that the majority of students agreed that they felt stressed due to barriers to accessibility of technology, followed by those who said they felt undecided on the matter and those who strongly agreed with the premise. It must be noted that the proportion of students who said they felt strongly 
psychologically impacted due to barriers to online learning outweighed the proportion of students who claimed they either disagreed or strongly disagreed with the premise. Overall, the results indicate that online learning has negatively impacted the psychology of students due to barriers to the accessibility of technology. Male and female results show that they are not continuous samples with equal medians (null hypothesis $h=1, p<0.05$ ) as shown in Table 2.

\subsection{Technology and Tools to Engage in Teamwork Activities}

Teamwork is an essential part of learning in certain modules. Oftentimes, lecturers expect the students to work together in small groups for assignments, coursework, and projects. However, working in groups fundamentally changed as the students worked from home and we wanted to know their opinion about the new mode of teamwork. As the study group consisted mainly of students from Generation $\mathrm{Z}$ who usually rely on social media for engaging with peers, it was interesting to see the results of the question based on engaging with peers for learning activities using similar technologies. So, we asked students whether they think they had adequate technology and tools to engage in teamwork as shown in Figure 6. The results show that the majority of both male and female students thought they had adequate technology and tools to engage in teamwork.

\section{Do you think you had adequate technology and tools to engage in teamwork activities?}

(a) Male students

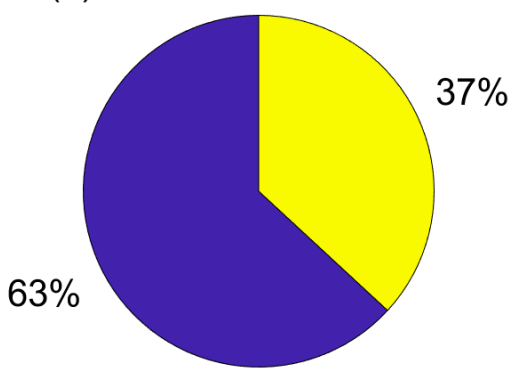

(b) Female students

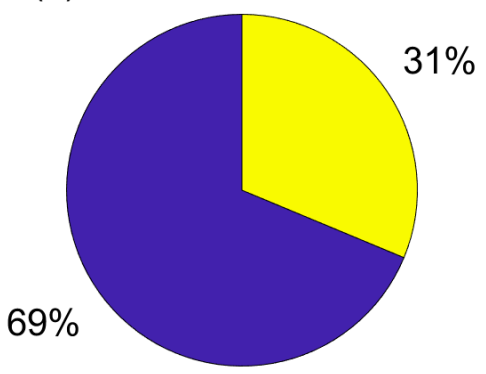

Figure 6. Student responses to "Do you think you had adequate technology and tools to engage in teamwork activities?" The blue shows those who responded "Yes" and the yellow shows those who responded "No".

\subsection{Confidence to Engage in Online Exams Based on Accessibility to Tools/Technology}

We asked students whether they feel confident to engage in online exams based on accessibility to tools/technology as shown in Figure 7. The results indicated that the majority of students agreed that they are confident to engage in online exams based on accessibility to tools/technology, followed up by those who are undecided and those who disagreed with the premise. It is noted that the proportion of students who said they strongly agree is greater than the proportion of students who said they strongly disagreed. Overall, we could observe that the students felt positive about engaging in online exams following the current system. Both male and female results show that they are continuous samples with equal medians (null hypothesis $h=0, p>0.05$ ) as shown in Table 3 . The median/central tendency of the results is indicated to be "agreed" on the topic as shown in Table 3. 


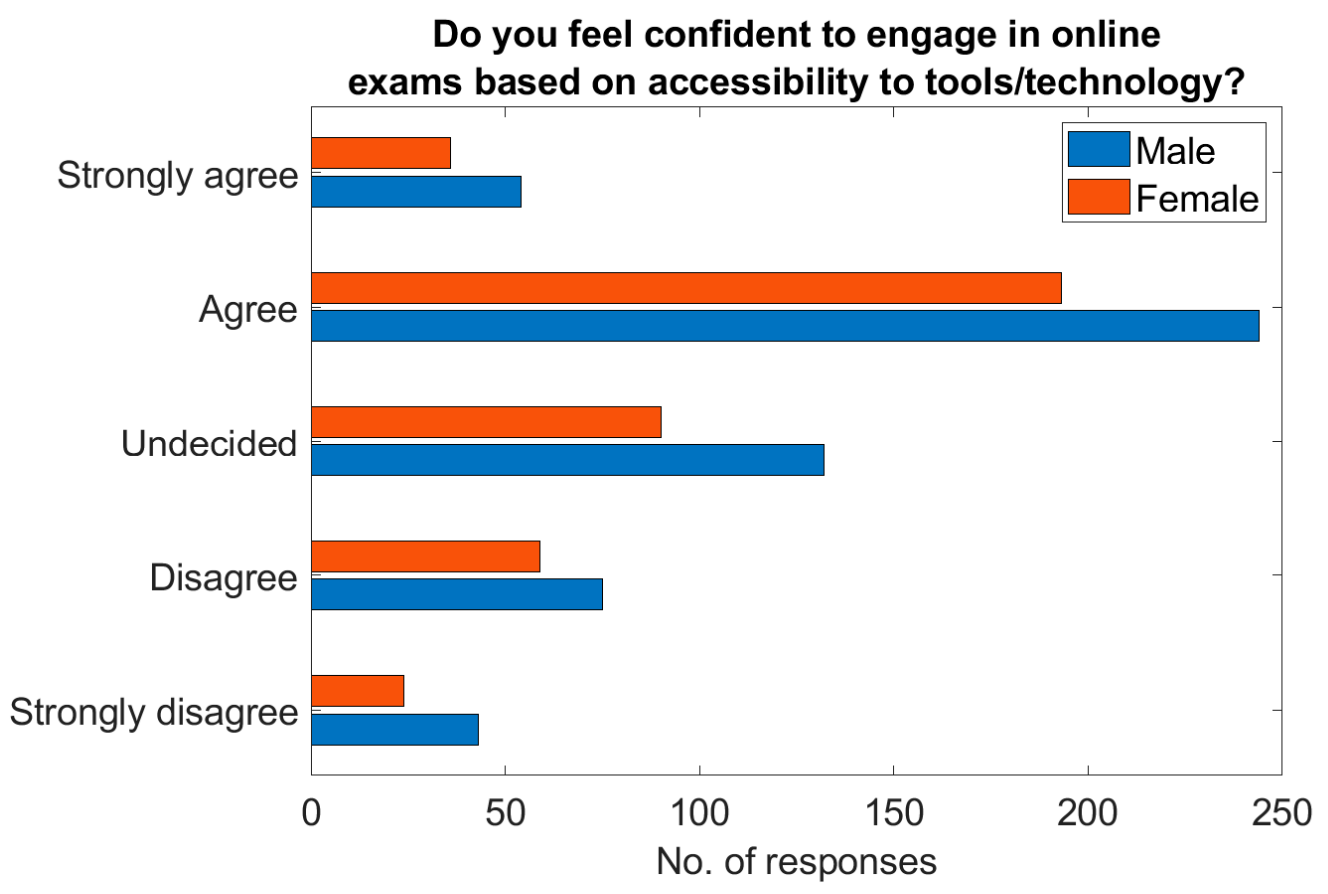

Figure 7. Student responses to “Do you feel confident to engage in online exams based on accessibility to tools/technology?"

Table 3. Mode, mean, and Mann-Whitney U test results for confidence to engage in online exams based on accessibility to tools/technology data.

\begin{tabular}{ccccc}
\hline & Mode & Mean & h (Null Hypothesis) & $p$-Value \\
\hline Male & 4 & 3.3485 & 0 & 0.5709 \\
Female & 4 & 3.3930 & & \\
\hline
\end{tabular}

\subsection{Disadvantages of Online Delivery of Teaching}

\subsubsection{Feeling Disadvantaged Due to Online Delivery}

Due to social-distancing regulations, the laboratory sessions were either postponed or conducted through lab demonstration videos or computer simulations. It is welldocumented that using the above-mentioned methods the students could not be equipped with the same hands-on experience that they would have otherwise received. With the limitations of online learning being studied, we obtained the students' perspective by asking whether they feel disadvantaged as a result of online delivery as shown in Figure 8. To this question, the students, both male and female, stated very clearly that they do feel disadvantaged.

\subsubsection{Delaying Study Programme until Face-to-Face Teaching Begins}

The present study group is surveyed following the institute's decision to continue all academic activities remotely using virtual learning platforms. At the same time, the students also may have observed other higher education institutions that opted to delay learning until face-to-face teaching was possible. So, we asked the students whether they would take the offer if they had the option to delay their program until face-to-face teaching could begin, whenever that might be, as shown in Figure 9. 


\section{Do you feel that you were disadvantaged as a result of online delivery?}

(a) Male students

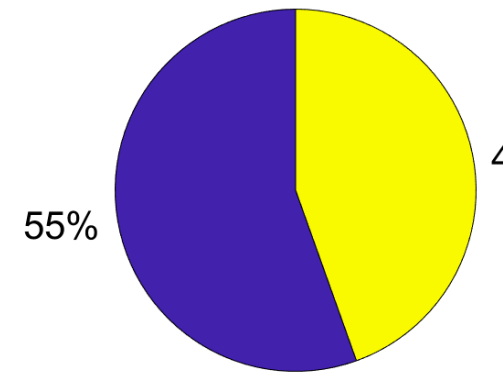

(b) Female students

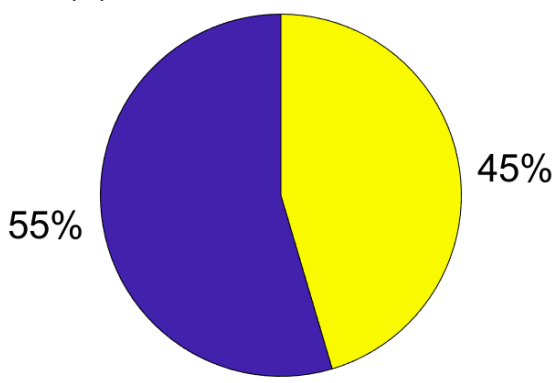

Figure 8. Student responses to "Do you feel that you were disadvantaged as a result of online delivery?" The blue shows those who responded "Yes" and the yellow shows those who responded "No".

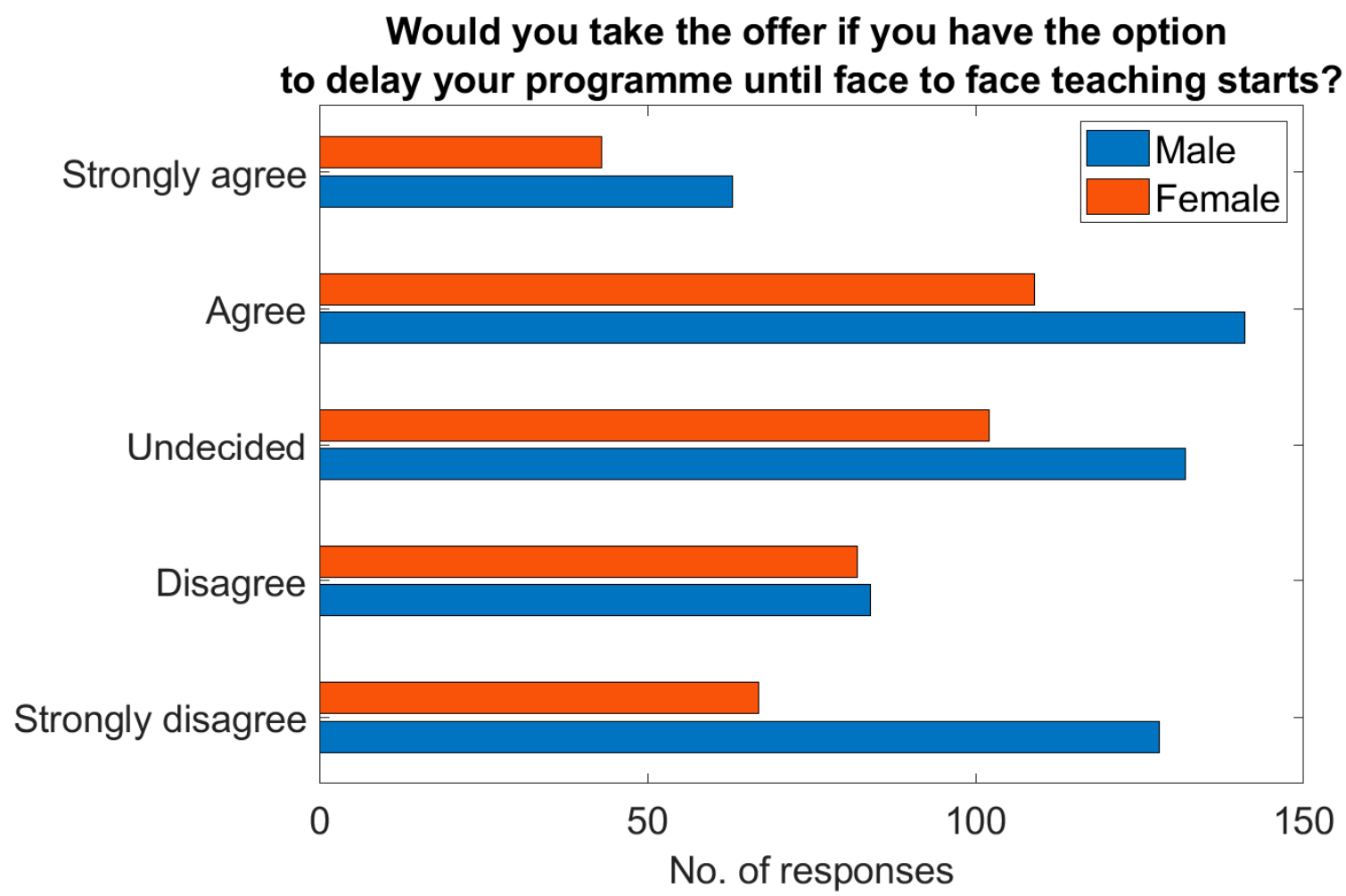

Figure 9. Student responses to "Would you take the offer if you have the option to delay your program until face-to-face teaching starts?"

The results in Figure 9 clearly indicate a split in opinion between male and female students, unlike in previous survey questions. Among male students, we noticed that the majority of students agreed that they would take the offer to delay their studies, followed up by a significant proportion of undecided students and those who strongly disagreed that learning should be delayed due to the pandemic. Among female students, we noticed that the majority of students also agreed with delaying learning, followed by those who are undecided and those who disagree with the premise.

Overall, the results indicate that on average, students are undecided on delaying their studies. Among male students, the sentiment is generally negative as they prefer not to delay their studies while among female students, the sentiment is positive as they prefer to delay their studies due to the pandemic. Both male and female results show that they 
are continuous samples with equal medians (null hypothesis $h=0, p>0.05$ ) as shown in Table 4. The median/central tendency of the results is indicated to be "undecided" on the topic as shown in Table 4.

Table 4. Mode, mean, and Mann-Whitney U test results for delaying study until face-to-face learning begins data.

\begin{tabular}{ccccc}
\hline & Mode & Mean & h (Null Hypothesis) & $p$-Value \\
\hline Male & 3 & 2.8668 & 0 & 0.3844 \\
Female & 3 & 2.9479 & & \\
\hline
\end{tabular}

\subsection{Confidence and Competency of Lecturers in Delivering Lectures Online Using Technology}

We asked the students whether they feel their lecturers are confident and competent in delivering teaching online and using technology as shown in Figure 10. The results indicated that the majority of both male and female students agreed that their lecturers are confident and competent on the job, which is followed by those who were undecided and those who disagreed with the premise. It is noted that the proportion of students who claimed to strongly agree with the premise overweighed the proportion of students who strongly disagreed. Both male and female results show that they are continuous samples with equal medians (null hypothesis $h=0, p>0.05$ ) as shown in Table 5. The median/central tendency of the results is indicated to be "agreed" on the topic as shown in Table 5.

Do you feel that lecturers are confident and competent in delivering teaching online and using technology?

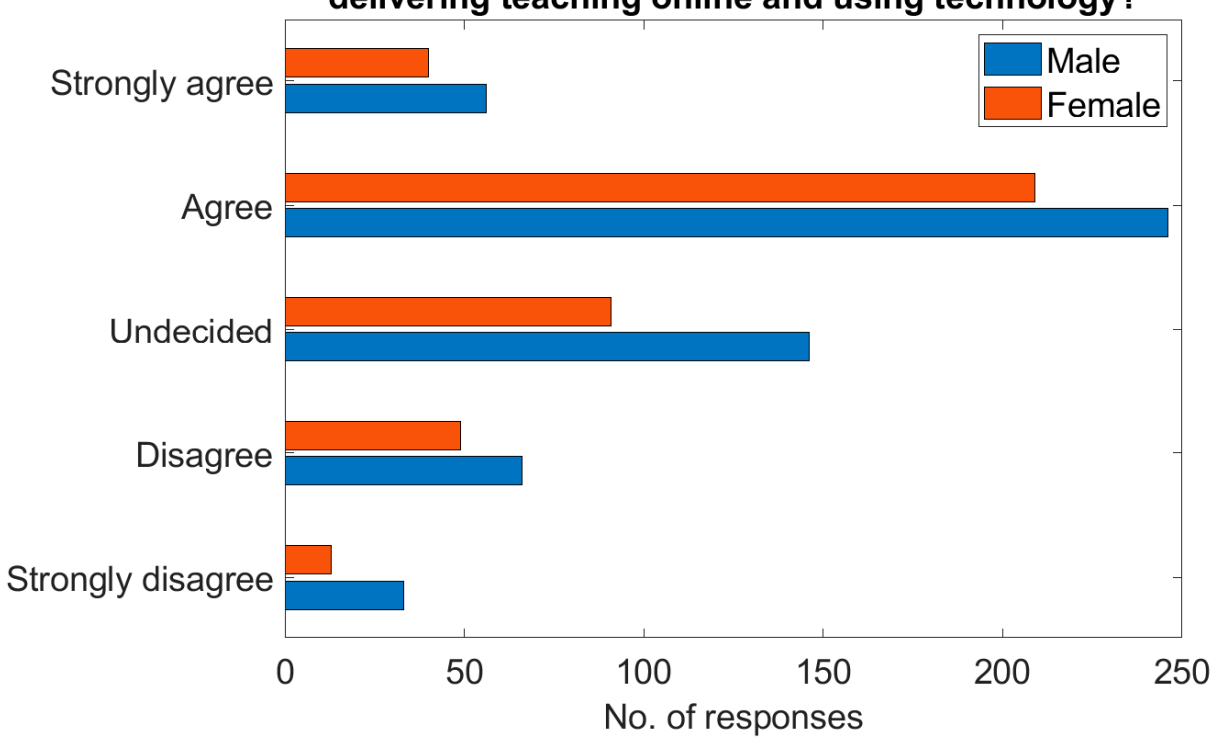

Figure 10. Student responses to "Do you feel that lecturers are confident and competent in delivering teaching online and using technology?"

Table 5. Mode, mean, and Mann-Whitney U test results for confidence and competency of lecturers in delivering lectures online using technology data.

\begin{tabular}{ccccc}
\hline & Mode & Mean & h (Null Hypothesis) & $p$-Value \\
\hline Male & 4 & 3.5323 & 0 & 0.0797 \\
Female & 4 & 3.4132 & & \\
\hline
\end{tabular}

\section{Discussion}

The device usage analysis showed that the most preferred device for online learning is a laptop, followed by a smartphone and desktop, lastly tablet. Furthermore, it was noted 
that the most relied on combinations of device use are laptop and smartphone, laptop only and smartphone only. The greater reliance on laptop and smartphone combinations indicates the possibility that students are depending on mobile internet to connect to lectures, especially in rural parts of the country. Additionally, smartphones may be used as a backup when attending lectures due to their relatively long battery life, greater portability, and easier accessibility due to lower cost. It is noted that there is a significant proportion of users of smartphones as the only medium for attending lectures. This trend has been identified in previous research focusing on similarly developing countries as well [17]. This could potentially be more prevalent in rural parts of the country where access to WiFi connections is limited therefore users depend on mobile internet for internet access. Conversely, it is noted that a very low proportion of students stated that they are using a desktop as their only medium for attending lectures. These trends highlight the importance of portability, the presence of in-built network components, and the cost of choosing the device for online learning. We see that smartphones could be a great equalizer in education in developing countries as they allow rural communities to connect to the internet and profit from the free resources available. In the development of rural communities, providing access to the internet through smartphones could be an avenue that governments of developing countries could analyze further.

In the study of the preferred mode of lecture delivery, it was identified that the most preferred mode of delivery was face-to-face learning. After face-to-face learning, the next preferred modes were hybrid and online modes of delivery. It must be noted that the results show students' natural affinity to physical interactions with lecturers and peers and they feel that this is the most effective mode of learning. This must be appreciated with the existing culture of learning, from pre-university days, and the ecosystem that has evolved around learning physically. In this eco-system, using the library for referring books/articles for further learning and meeting peers/lecturers are integral parts of the process. However, it is also noted that online and hybrid modes, while novel concepts to the surveyed students before the pandemic, have also become relatively popular alternatives for learning in a short period of time. In fact, if the students who preferred online or hybrid modes of study were combined, they would significantly outnumber the students who indicated preference over the traditional mode of learning. In both online and hybrid modes of learning, recorded lectures which can be viewed at the students' convenience would be available. It is possible that the students have adapted and grown an interest in the asynchronous mode of learning as well. Finally, we observed the same patterns of lecture delivery preferences between male and female students.

With regards to the preferred mode of learning, the responses could have been widely varying for the modules/programs being referred to by the respondents. For example, students enrolled in more practical-oriented modules in the engineering and music schools could have favored face-to-face learning more due to limitations in remote learning At the same time, classroom-based programs in the Business school could have favored the convenience of remote learning $[15,24]$. However, in the present survey, we limit ourselves to analyzing only the general trends with regards to online learning as observed across all schools.

From the survey, it was observed that the central tendency of both gender groups indicated they were undecided on the smoothness of the transition to online learning. Similarly, the students did not indicate clear agreement or disagreement of tools provided for coping with online learning and technologies as well as confidence about the knowledge and tools to learn online. Interestingly, both male and female students showed very similar sentiments in all these three areas. As the COVID-19 pandemic forced many institutes to quickly transition to an online mode of delivery, the students were also forced to do the same in a short period of time. Lack of previous experience in using online learning tools, device limitations, and connectivity issues could have made this transition more difficult and coping with the change a challenge for many students. 
An area where students showed general consensus was that they were stressed due to barriers to accessibility of technology while female students showed slightly more dissatisfaction than male students. This point was supported by the data collected on the devices used to access online learning: a high percentage of students relying on smartphones. It supported the notion that the students struggled to find suitable devices to attend online lectures, complete assignments, and online examinations evaluations on time which likely increased stress due to accessibility to technology. This also meant that the students were forced to develop new digital learning skills in a very short period of time. For example, the students were forced to use online tools such as Zoom and Moodle extensively. Additionally, independent learning was an essential skill they needed to develop as they transitioned to learning remotely.

In many programs, teamwork is an essential component of learning which would also enhance a lot of the soft skills of the learners. From the survey, it was noted that the majority of students, among both gender groups, considered that they had adequate technology and tools to engage in teamwork activities. This could be indicative of various modes of communication available through social media as well as in-built platforms in the learning management system which allows greater connectivity between students and lecturers. Notably, the type of device available did not likely affect the ability of a student to communicate for teamwork activities as most devices did provide many options to communicate effectively. The sentiment of a better teamwork environment using mobile devices was also shared in previous research [31].

The majority of students felt that online delivery was disadvantageous to them. This sentiment could have been influenced by the backdrop of many local institutions preferring to delay teaching and evaluations due to the pandemic. However, it should not take away from the fact that many students experienced difficulties with devices, connectivity and also many must have had difficulties in adapting so quickly to remote learning and independent learning. However, there was no general consensus for postponing education until face-to-face learning could restart as many saw the benefit of continuing their education despite the obstacles faced. These conflicting results could be explained by the fact that students indicated that they were generally satisfied with the competency of lecturers in teaching online and using technology. It supports the notion that the students have placed greater faith in the learning management system of the university which provides learning resources (including recorded lectures), assignments as well as online examinations. This is supported by the results obtained for confidence in engagement in online exams: a majority of students (from both gender groups) suggested that they were confident of engaging in online exams based on accessibility to technology.

\section{Conclusions}

The study presented the results of a comprehensive survey conducted to analyze students' online learning preferences and perspectives. It was found that the majority of students' preferred device combination for accessing online learning is laptop and smartphone, suggesting possible dependency on mobile internet. Further, it was noted the high dependency of smartphones for learning remotely during the pandemic. The popularity of the smartphone could be attributed to its portability, relatively long battery life, inbuilt internet facilities, and low cost. Then it was revealed that, nine months after shifting to the online mode of learning, students' preferred mode of learning is through face-to-face, despite online and hybrid modes having gained rapid popularity over a short period of time. The preference for face-to-face learning may not only be a result of the effectiveness of the learning but also due to the social interaction, low accessibility to devices/facilities, and an ecosystem in the education system which has evolved to cater only for the physical mode of learning.

The results presented in this survey may be comparable to an educational institute in a similarly developing country where access to devices/services and low preparedness to adapt to online learning might be significant issues. In the transition to online learning, 
we noted the important role played by smartphones which provided more equality in education as they provide a cheap, portable option with long battery life to bring internet access to regions that would otherwise not profit from the same benefits. We think that education policymakers should take proactive measures to develop mobile-based learning systems. In this regard, it is important to highlight a significant amount of training (or re-training) that will also need to be provided to rural communities.

In the survey, it is also shown how students in a developing country with limited resources perceive online learning in a time of crisis and could be used by educational policymakers to make predictions of student learning patterns in such dire times in the future. During the pandemic, we noted that it was very difficult to provide solutions for two main teaching problems: firstly, the need to conduct laboratory and other practical learning activities, and secondly online-based examinations maintaining a high level of exam integrity. For both of these problems, we found the alternatives required a significant amount of resources that developing countries often lacked. So, in future work, we would like to analyze these problems in depth and share the experiences of the authors when conducting these activities remotely while maintaining the quality and integrity of the academic programs.

Author Contributions: Conceptualization, E.P.; methodology, E.P. \& K.A.A.G.; investigation, E.P.; resources, E.P.; writing-original draft preparation, E.P.; writing-review and editing, K.A.A.G.; supervision, K.A.A.G.; project administration, E.P. \& K.A.A.G. All authors have read and agreed to the published version of the manuscript.

Funding: This work is funded by the European Commission grant number 619438-EPP-1-2020-1PK-EPPKA2-CBHE-JP and the Responsive Research Seed Grant of Sri Lanka Technological Campus, Padukka, Sri Lanka under grant no. RRSG/20/A6.

Institutional Review Board Statement: The survey was approved and conducted by the institution.

Informed Consent Statement: Informed consent was obtained from all subjects involved in the study.

Data Availability Statement: The data presented in this study are available on request from the corresponding author. The data are not publicly available due to privacy.

Acknowledgments: Authors would like to thank the support given by the Learning Management System Administrator/Quality Assurance Administration of Sri Lanka Technological Campus, Padukka, Sri Lanka for collecting survey data.

Conflicts of Interest: The authors declare no conflict of interest.

\section{References}

1. Eze, S.C.; Chinedu-Eze, V.C.; Bello, A.O. The utilisation of e-learning facilities in the educational delivery system of Nigeria: A study of M-University. Int. J. Educ. Technol. High. Educ. 2018, 15, 34. [CrossRef]

2. Agung, A.S.N.; Surtikanti, M.W. Students' Perception of Online Learning during COVID-19 Pandemic: A Case Study on the English Students of STKIP Pamane Talino. Soshum J. Sos. Hum. 2020, 10, 225-235. [CrossRef]

3. Jena, P.K. Online Learning during Lockdown Period for COVID-19 in India. Int. J. Multidiscip. Educ. Res. 2020, 9, 82-92.

4. Sit, J.W.; Chung, J.; Chow, M.C.; Wong, T.K. Experiences of online learning: Students' perspective. Nurse Educ. Today 2005, 25, 140-147. [CrossRef]

5. Dixon, K.; Pelliccione, L.; Dixon, R. Differing student views of online learning modes across two programs in an Australian university. Campus Wide Inf. Syst. 2005, 22, 140-147. [CrossRef]

6. Bryson, J.R.; Andres, L. COVID-19 and rapid adoption and improvisation of online teaching: Curating resources for extensive versus intensive online learning experiences. J. Geogr. High. Educ. 2020, 44, 608-623. [CrossRef]

7. Bergdahl, N.; Nouri, J.; Fors, U. Disengagement, engagement and digital skills in technology-enhanced learning. Educ. Inf. Technol. 2019, 25, 957-983. [CrossRef]

8. Comer, D.R.; Lenaghan, J.A.; Sengupta, K. Factors That Affect Students' Capacity to Fulfill the Role of Online Learner. J. Educ. Bus. 2015, 90, 145-155. [CrossRef]

9. Bharuthram, S.; Kies, C. Introducing e-learning in a South African Higher Education Institution: Challenges arising from an intervention and possible responses. Br. J. Educ. Technol. 2012, 44, 410-420. [CrossRef]

10. Besser, A.; Flett, G.L.; Zeigler-Hill, V. Adaptability to a sudden transition to online learning during the COVID-19 pandemic: Understanding the challenges for students. Scholarsh. Teach. Learn. Psychol. 2020. [CrossRef] 
11. Octaberlina, L.R.; Muslimin, A.I. Efl Students Perspective towards Online Learning Barriers and Alternatives Using Moodle/Google Classroom during Covid-19 Pandemic. Int. J. High. Educ. 2020, 9, 1-9. [CrossRef]

12. Dube, B. Rural online learning in the context of COVID 19 in South Africa: Evoking an inclusive education approach. Multidiscip. J. Educ. Res. 2020, 10, 135. [CrossRef]

13. Holt, E.A.; Heim, A.B.; Tessens, E.; Walker, R. Thanks for inviting me to the party: Virtual poster sessions as a way to connect in a time of disconnection. Ecol. Evol. 2020, 10, 12423-12430. [CrossRef] [PubMed]

14. İliç, U.; Arikan, Y.D. Analysis of Student Views on Foreign Language Learning in Second Life Environment. Turk. Online J. Qual. Inq. 2016, 7, 364-395.

15. Innes, A.; Kelly, F.; McCabe, L. An Evaluation of an Online Postgraduate Dementia Studies Program. Gerontol. Geriatr. Educ. 2012, 33, 364-382. [CrossRef]

16. Fillion, G.; Limayem, M.; Laferriere, T.; Mantha, R. Integrating information and communication technologies into higher education: Investigating onsite and online students' points of view. Open Learn. J. Open Distance e-Learn. 2009, 24, 223-240. [CrossRef]

17. Briz-Ponce, L.; Pereira, A.; Carvalho, L.; Juanes-Méndez, J.A.; García-Peñalvo, F.J. Learning with Mobile Technologies-Students' Behavior. Comput. Hum. Behav. 2017, 72, 612-620. [CrossRef]

18. Gemmell, I.; Harrison, R.; Clegg, J.; Reed, K. Internationalisation in online distance learning postgraduate education: A case study on student views on learning alongside students from other countries. Innov. Educ. Teach. Int. 2013, 52, 137-147. [CrossRef]

19. Dyment, J.; Downing, J.; Hill, A.; Smith, H. 'I did think it was a bit strange taking outdoor education online': Exploration of initial teacher education students' online learning experiences in a tertiary outdoor education unit. J. Adventure Educ. Outdoor Learn. 2018, 18, 70-85. [CrossRef]

20. Bradford, G.R. A relationship study of student satisfaction with learning online and cognitive load: Initial results. Int. High. Educ. 2011, 14, 217-226. [CrossRef]

21. Hrastinski, S. A theory of online learning as online participation. Comput. Educ. 2009, 52, 78-82. [CrossRef]

22. Vayre, E.; Vonthron, A.-M. Psychological Engagement of Students in Distance and Online Learning: Effects of Self-Efficacy and Psychosocial Processes. J. Educ. Comput. Res. 2017, 55, 197-218. [CrossRef]

23. Dziuban, C.; Moskal, P.; Thompson, J.; Kramer, L.; Decantis, G.; Hermsdorfer, A. Student Satisfaction with Online Learning: Is it a Psychological Contract? Online Learn. 2015, 19. [CrossRef]

24. Aguilera-Hermida, A.P. College students' use and acceptance of emergency online learning due to COVID-19. Int. J. Educ. Res. Open 2020, 1, 100011. [CrossRef]

25. Adnan, M.; Anwar, K. Online Learning amid the COVID-19 Pandemic: Students' Perspectives. Online Submiss. 2020, 2, 45-51. [CrossRef]

26. Mulenga, E.M.; Marbán, J.M. Prospective Teachers' Online Learning Mathematics Activities in The Age of COVID-19: A Cluster Analysis Approach. Eurasia J. Math. Sci. Technol. Educ. 2020, 16, em1872. [CrossRef]

27. Khalil, R.; Mansour, A.E.; Fadda, W.A.; Almisnid, K.; Aldamegh, M.; Al-Nafeesah, A.; Alkhalifah, A.; Al-Wutayd, O. The sudden transition to synchronized online learning during the COVID-19 pandemic in Saudi Arabia: A qualitative study exploring medical students' perspectives. BMC Med. Educ. 2020, 20,1-10. [CrossRef] [PubMed]

28. Jamieson, S. Likert scales: How to (ab)use them. Med. Educ. 2004, 38, 1217-1218. [CrossRef]

29. Norman, G. Likert Scales, Levels of Measurement and the "Laws" of Statistics. Adv. Health Sci. Educ. 2010, 15, 625-632. [CrossRef]

30. Clegg, F. Simple Statistics-A Coursebook for the Social Sciences; Cambridge University Press: Cambridge, UK, 1990.

31. Liu, Y. Social Media Tools as a Learning Resource. J. Educ. Technol. Dev. Exch. 2010, 3, 8. [CrossRef] 